\title{
Testing for Random Walk Behavior in Indian Bond Market
}

\author{
A. Sarath Babu \\ Finance and Accounting, Institute of Management Technology, Hyderabad, India \\ Email: sarathbabu@imthyderabad.edu.in
}

How to cite this paper: Babu, A.S. (2017) Testing for Random Walk Behavior in Indian Bond Market. Theoretical Economics Letters, 7, 728-736.

https://doi.org/10.4236/tel.2017.74052

Received: March 10, 2017

Accepted: May 16, 2017

Published: May 19, 2017

Copyright (C) 2017 by author and Scientific Research Publishing Inc. This work is licensed under the Creative Commons Attribution International License (CC BY 4.0).

http://creativecommons.org/licenses/by/4.0/

\begin{abstract}
This study examines the random walk behavior of Indian bond market. Bond indices published by Clearing Corporation of Indian (CCIL) were used in this study. The hypothesis is tested with multiple variance ratio tests from daily and weekly data, from 3-Jan.-2011 to 30-Dec.-2016. This paper also applies the bootstrap procedure on all the tests used because it shows desirable small sample properties under conditional heteroscedasticity. Variance test ratios show that Indian bond market does not follow random walk behavior.
\end{abstract}

\section{Keywords}

Random Walk Behavior, Individual Variance Ratio, Multiple Variance Ratios

\section{Introduction}

In the recent seven years, Indian bond market has seen tremendous growth. GSec market has grown by more than $500 \%$ in the last seven years, $29.1 \%$ compounded growth rate per annum. Table 1 shows growth rate of various debt market instruments from April 2008 to March 2015 in India. 91-day Treasury bill has grown by $37 \%$ p.a. for seven years; 364 -day T-Bill market has grown by $12 \%$. The reported data from Table 1 indicates that, Indian bond market has caught the attentions of investors. (FPI) is pumping money into Indian debt market, as yields of the country are stable. The bond market has attracted strong FPI's inflows; nearly $\$ 8$ billion in 2015 in addition to $\$ 26.2$ billion in 2014. In the last few years, improvement in the macroeconomic indicators has made the Indian debt market as one of the preferred investment destinations for investors.

The possibility that the Indian debt market will become the primary debt market in Asia suggests the importance of understanding the efficiency of Indian debt market.

This study examines the efficient market hypothesis (EMH) for Indian G-Sec 
Table 1. Turnover growth of Indian bond market.

\begin{tabular}{ccccc}
\hline Markets & $\begin{array}{c}\text { Mar.-15 } \\
\text { (in Billions) }\end{array}$ & $\begin{array}{c}\text { Apr.-08 } \\
\text { (in Billions) }\end{array}$ & Growth & CAGR \\
\hline CBLO & 1794.44 & 673.98 & $266 \%$ & $15.02 \%$ \\
Market Repo & 1097.57 & 382.99 & $287 \%$ & $16.23 \%$ \\
G-Sec & 553.07 & 92.58 & $597 \%$ & $29.09 \%$ \\
91-Day (T-Bill) & 33.31 & 3.68 & $905 \%$ & $36.99 \%$ \\
182-Day (T-Bill) & 12.09 & 2.02 & $599 \%$ & $29.13 \%$ \\
364-Day (T-Bill) & 19.02 & 8.39 & $227 \%$ & $12.40 \%$ \\
\hline
\end{tabular}

Source: Data base on Indian Economy, RBI's data warehouse. CAGR: Calculated by (Mar.-15/ Apr.-08)^(1/7)-1.

market through variance ratios. The idea of asset prices following random walk comes from Efficient Market Hypothesis (EMH). The assumption is that investors act immediately to any informational advantage, thereby, eliminating profit. Hence, prices fully reflect the information. This condition leads to a random walk behavior, random sequence of price changes, where the market is efficient. A random walk is defined as price changes are independent. If the Indian bond market follows random walk behavior, then the market is weak form of efficient and therefore, not predictable. This means it is impossible for a trader to generate excess return overtime by speculation. Otherwise, if the Indian bond market is predictable, then the market is not weak-form efficient, which means that traders can make excess profit by speculative positions. There have been many researches which test for the efficient market hypothesis of stock price.

\section{Literature Review}

A number of studies tested the efficient market hypothesis for diffident class of assets. Ojah and Karemera [1] employed multiple variance ratio and auto-regressive tests using data of US-dollar-based national equity indices. It was found that emerging equity market prices of Argentina, Brazil, Chile and Mexico are efficient based on multiple variance ratio test. Sonje et al. [2] examined the daily and monthly data of Croatia (Zagreb Stock Exchange) and US stock markets New York Stock Exchange (NYSE) for the period 1997 to 2010 using autocorrelation test to find out the simple trading rule that would exceed returns of stock index in the long run. It was found that daily data indicate a high degree of efficiency in the US markets before crisis but the Croatian markets were inefficient but not at the highest level of confidence. Borges [3] investigated the weak form of efficiency for the Portuguese Benchmark Index (PSI20), index of Lisbon Stock Market, from 1991 to 2006 using serial correlation test, run test, ADF test and multiple variance ratio tests. The data taken for study are further categorized into daily, weekly and monthly returns for the whole period and five different sub-periods showing different trends in the markets. Mixed evidences are found out on the whole and the results revealed that the PSE follows random walk behavior since 2000 with a decrease in the serial dependence of returns. 
Ajayi and Karemera [4], Lee et al. [5], Lima and Tabak [6], Azad [7] and Sasikumar [8] examined the foreign exchange rates of Asian countries such as Hong Kong dollar, Indo-nesian rupia, Korean won, Malaysian ringgit, Philippine peso, Singaporean dollar, Tai-wanese dollar and Indian rupees. Ajayi and Karamera [4] rejected the efficient market hypotheis for majority of the markets using Lo-Mackinlay's variance ratio test. Lee et al. [5] used Cecchetti-Lam's multiple variance tests with bootstrap method and identified evidence for serial correlation for major curries except Korean one. Lima and Tabak [6] found that the efficient market hypothesis cannot be rejected for the exchange rates emerging markets. Azad [7] confirmed the findings of Lima and Tabak [6] using Wright's test. Sasikumar [8] rejected the efficient market hypothesis for Indian foreign exchange market using multiple VR test.

While many studies available for foreign market, only few studies reported for Indian stock market and no studies found for debt market in India to test EMH, at least to the knowledge of author. Bhattacharya et al. [9], Jana and Meher [10] and Kumar and Maheswaran [11] have studied efficiency of Indian stock market. While the studies carried on foreign stock market and exchange market provide mixed response, studies carried on Indian stock market reject the efficient market hypothesis. Sarkar and Mukhopadhyay [9], Kumar and Maheswaran [11] have applied variance tests; Jana and Meher [10] have applied GARCH and Serial Correlation test for their studies.

There have been numerous empirical studies which test the market efficiency through different methods however majority of the researchers have applied variance ratio test for testing random walk behavior of assets. Hence, this paper applies variance ratio test to test RWH. Many researchers have studied RWH for different markets such as stock market, forex market, commodity market etc. No studies have been found to understand the efficiency of Indian bond market at least to the knowledge of the author. As the Indian bond market has gaining attentions of the international investors, it is imperative for the investors to know efficiency of the market whereby investors can adjust their risk level for investment in the bond market or try to make speculative profits.

\section{Variance Test}

The most popular statistical tool to test the RWH is variance test ratio [1] [3] [4] [5] [8] [9] [11]. Hence this paper applies Variance Ratio (VR) test to examine the efficient market hypothesis of Indian bond market. Variance test ratio was originally proposed by Lo \& Mackinlay [12] a number of alternative VR test have been proposed. They are based on the property that, if the time series of an asset return is purely random, the variance of $q$-period return is $q$ times the variance of one period return, i.e. the sample variance of $k$-period return $\left(Y_{t}-\right.$ $\left.Y_{t-q}\right)$, of the time series $Y_{t}$ is $q$ times the sample variance of one-period return $\left(Y_{t}\right.$ $\left.-Y_{t-1}\right)$. Hence, variance ratio at lag $q$ is defined as the ratio between $(1 / q)$ th of the $q$-period return to the variance of one-period return. Thus, the variance computed at each lag should be equal to unity. Thus, the variance ratio test eva- 
luates the hypothesis that a given time series follows a random walk return sequence. The variance ratio, $V R(q)$, is defined as follows.

$$
\operatorname{VR}(q)=\frac{\sigma^{2}(q)}{\sigma^{2}(1)}
$$

where $\sigma^{2}(q)$ is the unbiased return variance of $q$ period $\left(X_{t}-X_{t-q}\right)$ and $\sigma^{2}(1)$ is variance of one period $\left(X_{t}-X_{t-1}\right)$. The null hypothesis of random walk behaviour is that $V R(q)$ is not statistically different from unity.

The estimator of $q$ period return variance $\sigma^{2}(q)$ using $q$ period returns $\left(X_{t}+\cdots+X_{t-q+1}\right)$ calculated using overlaping on horizon returns ( $q$-period) as advocated by Lo and Mackinlay [12] and it is defined as show below

$$
\sigma^{2}(q)=m^{-1} \sum_{t=q}^{T}\left(x_{t}+x_{t-1}+\cdots+x_{t-q+1}-q \mu\right)^{2}
$$

where $\mu=T^{-1} \sum_{t=1}^{T} x_{t}$ and $m=q(T-q+1)\left(1-q T^{-1}\right)$. The value of $m$ is such as $\sigma^{2}(q)$ is an unbiased estimator of $q$ period return variance when $\sigma^{2}(1)$ is stationary over time.

This paper also consider joint variance ratio test of Chow and Denning [13]. Variance ratio test proposed by Lo and Macinlay [12] tests whether variance ratio is unity for particular holding period $(q)$ whereas variance ratio test of Chow and Dennings [13] tests variance ratios over number of holding periods are jointly equal to unity.

Lo and Mackinlay [12] variance test assumes that sampling distribution follows asymptotic properties, mostly which is not true with small samples. Variance ratio statistic can be far from standard normal distribution in case of small distribution with severe bias and right skewed. This can result in misleading statistical inference. Therefore, RWH requires that variance ratios for all the periods should be unity, conducted jointly over a number of holding periods.

To control the error in conventional variance ratio test, Chow and Denning [13] extends Lo and MacKinlay's [12] conventional variance ratio test methodology to a simple power transformation of VR statistic, when $q$ is not too large enough. Under this method the transformed VR statistics leads to significant gains mean-reverting alternatives. Variance ratio statistics defined as follows

$$
V R(p)=\frac{1}{(1-k / T)} \frac{4 \pi}{T \sigma^{2}} \sum_{j=1}^{(T-1) / 2} \frac{W_{q}\left(\vartheta_{i}\right)}{\Delta x \vartheta_{j}}
$$

where

$$
\begin{gathered}
\Delta x \vartheta_{j}=2 \pi T^{-1}\left|\sum_{i=1}^{T}\left(y-y_{(t-1)}-\mu\right) \exp (-i \vartheta t)\right|^{2} \\
W_{q}\left(\vartheta_{i}\right)=\sum_{|j|<q}\left(1-\frac{|j|}{q}\right) \exp (-i j \vartheta)
\end{gathered}
$$

A non-parametric alternative to conventional asymptotic VR tests using ranks and signs also applied. The tests based on ranks are exact under the independence and identical distribution assumption [14]. Wright [14] proves that rank based tests display low size distortion under conditional hetroscedasticity. 


$$
R_{j}(q)=\left((T q)^{-j} \sum_{t=q}^{T} \frac{\left(r_{j, t}+\cdots+r_{j, t-k+1}\right)^{2}}{T^{-1} \sum_{t=q}^{T} r_{j, t}^{2}}\right) X \varnothing(q)^{-1 / 2}
$$

Using several $q$ values would lead to an over rejection of the null hypothesis. To control this problem, Belaire-Franch and Contreras [15] proposed muliple rank and sign VR test and the same has been followed in this paper.

\section{Data and Descriptive Statistics}

The data examined consist of the daily and weekly index return for bond indices published by Clearing Corporation of India (CCIL). CCIL publishes bond indices for different tenors. All bond index (BI), sovereign bond index (SV), tenor indices such as zero to five ( 0 to 5 ), five to ten ( 5 to 10$)$ years, ten to fifteen (10 to 15 ) and fifteen to twenty (15 to 20 ) and twenty to thirty (20 to 30 ) are examined in this paper. The data span from January 4, 2011 to December 30, 2016, namely 2185 and 313 observations for the daily and weekly data respectively. For weekly data, the prices were observed on Wednesday or on the following day if the market is closed on Wednesday.

Table 2 presents descriptive statistics for the return series, calculated as the first difference in the logarithm of the index values for daily data. The tenor bonds 15 to 20 and 20 to 30 have the best performance although they are most volatile indices. The Jargue-Bera statistic is significant at the $5 \%$ level for all the indices, suggesting that returns are highly non-normal. Excess kurtosis also indicates that the empirical distribution of returns have fat tails. The Ljung-Box LB statistics for testing serial correlation show that all the series are not significantly serially correlated. To test the heteroscedasticity Ljung-Box LB2 and LM test of Engle have been used. These two statistics are significant, indicating that all indices have presence of conditional heteroscedasticity. Hence, this research has used VR test based on heteroscedasticity adjusted statistic.

For the weekly data (Table 3), all the returns show excess skewness and kurtosis and are non-normally distributed. All the returns are not serially correlated. Only 10 to 20, BI and SI are not exhibit heteroscasdasticity. These three indices were not employed hetroscadasticity adjusted statistic for variance ratio.

Tables 4-7 report results of individual and multiple variance test for the daily and weekly index return of Indian bond market. The holding periods $q$ considered are 2, 4, 8, 16 as suggested by Deo and Richardson [16]. The variance test statistic is reported for rank and sign based test $\mathrm{CD}(r)$ and $\mathrm{CD}(s)$ tests. Besides, the tables report $\operatorname{VR}(q)$ and $\mathrm{QB}(q)$ tests.

The random walk hypothesis for Indian bond market is rejected as per the variance ratio test. The $p$ values for all the small period $k(2,4,8,16)$ are less than $5 \%$ for $\operatorname{VR}(q)$. This indicates that players in the Indian bond market do not take risky positions in short term. The random walk hypothesis is rejected for the weekly data as well for all the indices.

The estimates of variance ratios are shown in the main row, the $\operatorname{VR}(q)$ statitics are in parenthesis, the $p$-values are in brackets. 
Table 2. Descriptive statistics for daily bond index return.

\begin{tabular}{|c|c|c|c|c|c|c|c|c|}
\hline & Mean & Std. Dev. & Skewness & Kurtosis & JB & LB (10) & LB2 (10) & LM (10) \\
\hline 0 to 5 & 0.00022 & 0.00135 & -0.48850 & 63.35802 & $331608.1^{*}$ & $32.57^{\star}$ & $329.58^{*}$ & $59.17^{\star}$ \\
\hline 5 to 10 & 0.00024 & 0.00214 & 0.29549 & 91.07838 & $705991.7^{*}$ & $28.12^{\star}$ & $204.37^{\star}$ & $50.38^{\star}$ \\
\hline 10 to 15 & 0.00026 & 0.00290 & 1.32367 & 100.68970 & $869076.8^{*}$ & $34.68^{\star}$ & $167.7^{\star}$ & $14.37^{\star}$ \\
\hline 15 to 20 & 0.00027 & 0.00317 & 0.72653 & 64.02131 & $339039.8^{*}$ & $21.85^{\star}$ & $76.66^{*}$ & $95.16^{*}$ \\
\hline 20 to 30 & 0.00027 & 0.00347 & 0.34913 & 63.87009 & $337214.7^{\star}$ & $23.66^{*}$ & $79.47^{\star}$ & $92.02^{*}$ \\
\hline BI & 0.00025 & 0.00228 & 0.83081 & 94.79217 & $766999.2^{*}$ & $25.76^{\star}$ & $129.42^{*}$ & $21.90^{*}$ \\
\hline SB & 0.00025 & 0.00229 & 0.76452 & 82.71783 & $577981.8^{*}$ & $20.04^{\star}$ & $105.88^{*}$ & $25.84^{*}$ \\
\hline
\end{tabular}

Table 3. Descriptive statistics for weekly bond index return.

\begin{tabular}{ccccccccc}
\hline Bond type & Mean & Std. Dev. & Skewness & Kurtosis & JB & LB (10) & LB2 (10) & LM \\
\hline 0 to 5 & 0.001545 & 0.003258 & 1.70988 & 14.00902 & $1727.61^{*}$ & $23.56^{*}$ & $149.38^{*}$ & $12.02^{* *}$ \\
5 to 10 & 0.001694 & 0.005306 & 0.77518 & 8.02916 & $360.05^{*}$ & $19.96^{*}$ & $223.11^{*}$ & $52.74^{*}$ \\
10 to 15 & 0.001776 & 0.007457 & 1.19397 & 10.00555 & $712.14^{*}$ & $15.85^{*}$ & 160.16 & 5.10 \\
15 to 20 & 0.001891 & 0.008715 & 1.11177 & 9.07152 & $543.50^{*}$ & $25.55^{*}$ & $111.78^{*}$ & $10.00^{*}$ \\
20 to 30 & 0.001902 & 0.0102 & 1.06948 & 8.97137 & $523.03^{*}$ & $24.16^{*}$ & $128.33^{*}$ & $22.62^{*}$ \\
BI & 0.001741 & 0.006212 & 1.24213 & 11.08382 & $929.76^{*}$ & $20.09^{\star}$ & 131.63 & 6.17 \\
SI & 0.001749 & 0.006494 & 1.01796 & 9.23810 & $556.18^{*}$ & $17.12^{*}$ & $145.72^{*}$ & 6.99 \\
\hline
\end{tabular}

Table 4. Individual variance ration test results for daily data.

\begin{tabular}{|c|c|c|c|c|}
\hline & 2 & 4 & 8 & 16 \\
\hline & 0.5549 & 0.2609 & 0.1285 & 0.0826 \\
\hline \multirow[t]{3}{*}{0 to 5} & $(-4.6645)$ & $(-4.6827)$ & $(-4.2328)$ & $(-3.8094)$ \\
\hline & [0000] & {$[0000]$} & [0000] & {$[0.0001]$} \\
\hline & 0.5561 & 0.2712 & 0.1254 & 0.0845 \\
\hline \multirow[t]{3}{*}{5 to 10} & $(-3.7082)$ & $(-3.7308)$ & $(-3.4169)$ & $(-3.0818)$ \\
\hline & {$[0.0002]$} & {$[0.0002]$} & {$[0.0006]$} & {$[0.0021]$} \\
\hline & 0.5290 & 0.2553 & 0.1229 & 0.0816 \\
\hline \multirow[t]{3}{*}{10 to 15} & $(-3.3161)$ & $(-3.3126)$ & $(-3.081)$ & $(-2.8275)$ \\
\hline & [0.0009] & [0.0009] & {$[0.0021]$} & [0.0047] \\
\hline & 0.5186 & 0.2603 & 0.1311 & 0.0839 \\
\hline \multirow[t]{3}{*}{15 to 20} & $(-4.6061)$ & $(-4.4957)$ & $(-4.0906)$ & $(-3.7348)$ \\
\hline & {$[0000]$} & {$[0000]$} & {$[0000]$} & {$[0.0002]$} \\
\hline & 0.5398 & 0.2703 & 0.1354 & 0.0903 \\
\hline \multirow[t]{3}{*}{20 to 30} & $(-4.5526)$ & $(-4.4608)$ & $(-4.0519)$ & $(-3.7096)$ \\
\hline & {$[0000]$} & {$[0000]$} & {$[0.0001]$} & {$[0.0002]$} \\
\hline & 0.5667 & 0.2733 & 0.1320 & 0.0879 \\
\hline \multirow[t]{3}{*}{ Bond Index } & $(-3.305)$ & $(-3.4467)$ & $(-3.2122)$ & $(-2.974)$ \\
\hline & [0.0009] & {$[0.0006]$} & {$[0.0013]$} & [0.0029] \\
\hline & 0.5706 & 0.2778 & 0.1352 & 0.0896 \\
\hline \multirow[t]{2}{*}{ Sovereign Bonds } & $(-3.485)$ & $(-3.6419)$ & $(-3.408)$ & $(-3.1782)$ \\
\hline & {$[0.0005]$} & {$[0.0003]$} & {$[0.0007]$} & {$[0.0015]$} \\
\hline
\end{tabular}


Table 5. Multiple variance ratio test results for daily data.

\begin{tabular}{cccc}
\hline & QB & $\mathrm{CD}(r)$ & $\mathrm{CD}(s)$ \\
\hline $\mathbf{0}$ to 5 & 4.683 & 19.892 & 12.136 \\
\multirow{2}{*}{5 to 10} & {$[0000]$} & {$[0000]$} & {$[0000]$} \\
& 3.731 & 18.368 & 10.937 \\
$\mathbf{1 0}$ to 15 & {$[0.001]$} & {$[0000]$} & {$[0000]$} \\
& 3.316 & 18.333 & 10.937 \\
$\mathbf{1 5}$ to 20 & {$[0.001]$} & {$[0000]$} & {$[0000]$} \\
& 4.606 & 19.016 & 12.435 \\
20 to 30 & {$[0000]$} & {$[0000]$} & {$[0000]$} \\
& 4.553 & 18.749 & 11.964 \\
Bond Index & {$[0.002]$} & {$[0000]$} & {$[0000]$} \\
& 3.447 & 16.755 & 11.108 \\
& {$[0.001]$} & {$[0000]$} & {$[0000]$} \\
Sovereign Bonds & 3.642 & 17.326 & 12.392 \\
& {$[0000]$} & {$[0000]$} & {$[0000]$} \\
\hline
\end{tabular}

Table 6. Individual variance ration test results for Weekly data.

\begin{tabular}{|c|c|c|c|c|}
\hline & 2 & 4 & 8 & 16 \\
\hline & 0.4888 & 0.2233 & 0.1465 & 0.0619 \\
\hline \multirow[t]{3}{*}{0 to 5} & $(-3.3372)$ & $(-2.8197)$ & $(-2.1248)$ & $(-1.7222)$ \\
\hline & {$[0.0008]$} & {$[0.0048]$} & {$[0.0336]$} & {$[0.085]$} \\
\hline & 0.5068 & 0.2295 & 0.1510 & 0.0668 \\
\hline \multirow[t]{3}{*}{5 to 10} & $(-3.1283)$ & $(-2.8273)$ & $(-2.2452)$ & $(-1.8862)$ \\
\hline & {$[0.0018]$} & [0.0047] & {$[0.0248]$} & [0.0593] \\
\hline & 0.4967 & 0.2221 & 0.1413 & 0.0664 \\
\hline \multirow[t]{3}{*}{10 to 15} & $(-3.5888)$ & $(-3.1658)$ & $(-2.3835)$ & $(-1.859)$ \\
\hline & {$[0.0003]$} & {$[0.0015]$} & {$[0.0171]$} & {$[0.063]$} \\
\hline & 0.5563 & 0.2317 & 0.1567 & 0.0726 \\
\hline \multirow[t]{3}{*}{15 to 20} & $(-3.9881)$ & $(-3.9447)$ & $(-2.8257)$ & $(-2.1263)$ \\
\hline & {$[0.0001]$} & [0.0001] & [0.0047] & {$[0.0335]$} \\
\hline & 0.5164 & 0.2324 & 0.1530 & 0.0698 \\
\hline \multirow[t]{3}{*}{20 to 30} & $(-3.568)$ & $(-3.36)$ & $(-2.5474)$ & $(-2.003)$ \\
\hline & {$[0.0004]$} & [0.0008] & [0.0109] & [0.0452] \\
\hline & 0.5011 & 0.2254 & 0.1480 & 0.0675 \\
\hline \multirow[t]{3}{*}{$\begin{array}{l}\text { Bond } \\
\text { Index }\end{array}$} & $(-3.4821)$ & $(-3.1395)$ & $(-2.3742)$ & $(-1.8409)$ \\
\hline & {$[0.0005]$} & {$[0.0017]$} & {$[0.0176]$} & {$[0.0656]$} \\
\hline & 0.4985 & 0.2330 & 0.1498 & 0.0683 \\
\hline \multirow[t]{2}{*}{ Sovereign Bonds } & $(-3.6401)$ & $(-3.235)$ & $(-2.4767)$ & $(-1.9398)$ \\
\hline & {$[0.0003]$} & {$[0.0012]$} & [0.0133] & {$[0.0524]$} \\
\hline
\end{tabular}


Table 7. Multiple variance ration test results for weekly data.

\begin{tabular}{cccc}
\hline & QB & $\mathrm{CD}(\boldsymbol{r})$ & $\mathrm{CD}(s)$ \\
\hline $\mathbf{0}$ to 5 & 3.337 & 7.120 & 4.933 \\
\multirow{2}{*}{5 to 10} & {$[0.0034]$} & {$[0000]$} & {$[0000]$} \\
& 3.128 & 6.328 & 4.547 \\
10 to 15 & {$[0.007]$} & {$[0000]$} & {$[0000]$} \\
& 3.589 & 7.248 & 5.727 \\
15 to 20 & {$[0.0013]$} & {$[0000]$} & {$[0000]$} \\
& 3.988 & 6.429 & 4.933 \\
20 to 30 & {$[0.0003]$} & {$[0000]$} & {$[0000]$} \\
& 3.568 & 6.742 & 4.593 \\
Bond Index & {$[0.0014]$} & {$[0000]$} & {$[0000]$} \\
& 3.482 & 6.584 & 5.274 \\
Soverign Bonds & {$[0.002]$} & {$[0000]$} & {$[0000]$} \\
& 3.640 & 6.684 & 5.500 \\
\hline
\end{tabular}

\section{Conclusion}

This study employed individual and multiple variance tests to assess the random walk hypothesis of Indian bond market using bond indices published by the CCIL. Analyzing the data from $3^{\text {rd }}$ Jan. 2011 to $30^{\text {th }}$ Dec. 2016 daily and weekly data, RWH is rejected for Indian bond market. Variance tests applied to test the $\mathrm{RWH}$ are robust to heteroscedasticity and non-normality. The outcome of the analysis suggesting that possibility of abnormal returns through speculation in the Indian bond market by traders is present to a great extent.

\section{References}

[1] Ojah, K. and Karemera, D. (1999) Random Walks and Market Efficiency Tests of Latin American Emerging Equity Markets: A Revisit. The Financial Review, 34, 5772. https://doi.org/10.1111/j.1540-6288.1999.tb00454.x

[2] Sonje, V., Alajbeg, D. and Babus, Z. (2011) Efficient Market Hypothesis: Is the Croatian Stock Market as (In)Efficient as the US Market. Financial Theory and Practice, 35, 301-326. https://doi.org/10.3326/fintp.35.3.3

[3] Borges, M.R. (2009) Random Walk Tests for the Lisbon Stock Market. Applied Economics, 43, 631-665.

[4] Ajayi, R.A. and Karemera, D. (1996) A Variance Ratio Test of Random Walks in Exchange Rates: Evidence from Pacific Basin Economies. Pacific-Basin Finance Journal, 4, 77-91.

[5] Lee, C.I., Pan, M.S. and Liu, Y.A. (2001) On Market Efficiency of Asian Foreign Exchange Rates: Evidence from a Joint Variance Ratio Test and Technical Trading Rules. Journal of International Financial Markets, Institutions \& Money, 11, 199214.

[6] Lima, E.J.A. and Tabak, B.M. (2007) Building Confidence Intervals with Block 
Bootstraps for the Variance Ratio Test of Predictability. Working Papers Series.

[7] Azad, A.S.M. (2009) Random Walk and Efficiency Tests in the Asia-Pacific Foreign Exchange Markets: Evidence from the Post-Asian Currency Crisis Data. Research in International Business and Finance, 23, 322-338.

[8] Sasikumar, A. (2011) Testing for Weak Form Market Efficiency in Indian Foreign Exchange Market. The IUP Journal of Monetary Economics, 9, 7-19.

[9] Bhattacharya, K., Sarkar, N. and Mukhopadhyay, D. (2003) Stability of the Day of the Week Effect in Return and in Volatility at the Indian Capital Market: A GARCH Approach with Proper Mean Specification. Applied Financial Economics, 13, 553563. https://doi.org/10.1080/0960310021000020924

[10] Jana, S. and Meher, K.C. (2012) On the Validity of the Weak Form of Efficient Market Hypothesis Applied to National Stock Exchange of India (NSE) and Bombay Stock Exchange of India (BSE). International Journal of Business and Management Tomorrow, 2.

[11] Kumar, D. and Maheswaran, S. (2013) Are Major Asian Markets Efficient? An Analysis Using Non-Parametric Joint Variance Ratio Tests. Journal of Management Research, 13, 3-10.

[12] Lo, A. and MacKinlay, A. (1988) Stock Market Prices Do Not Follow Random Walk: Evidence from a Simple Specification Test. The Review of Finance Studies, 1, 41-66. https://doi.org/10.1093/rfs/1.1.41

[13] Chow, K. and Denning, K. (1993) A Simple Multiple Variance Ratio Test. Journal of Econometrics, 58, 385-401.

[14] Wright, J. (2000) Alternative Variance-Ratio Tests Using Ranks and Signs. Journal of Business and Economic Statistics, 18, 1-9. https://doi.org/10.1080/07350015.2000.10524842

[15] Belaire-Franch, J. and Contreras, D. (2004) Ranks and Sign Based Multiple Variance Ratio Tests. Working Paper.

[16] Deo, R. and Richardson, M. (2003) On the Asymptotic Power of the Variance Ratio Test. Econometric Theory, 19, 231-239. https://doi.org/10.1017/S0266466603192018

Submit or recommend next manuscript to SCIRP and we will provide best service for you:

Accepting pre-submission inquiries through Email, Facebook, LinkedIn, Twitter, etc.

A wide selection of journals (inclusive of 9 subjects, more than 200 journals)

Providing 24-hour high-quality service

User-friendly online submission system

Fair and swift peer-review system

Efficient typesetting and proofreading procedure

Display of the result of downloads and visits, as well as the number of cited articles

Maximum dissemination of your research work

Submit your manuscript at: http://papersubmission.scirp.org/

Or contact tel@scirp.org 